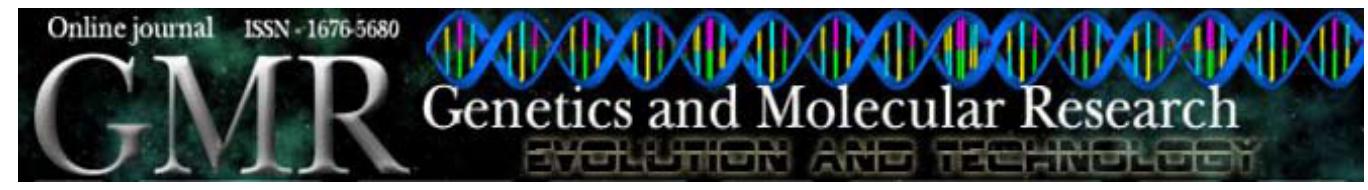

\title{
Relationship between genetic polymorphism of MCP-1 and non-small-cell lung cancer in the Han nationality of North China
}

\author{
L. Yang ${ }^{1}$, G.L. Shi ${ }^{2}$, C.X. Song ${ }^{2}$ and S.F. Xu ${ }^{1}$ \\ ${ }^{1}$ Department of Thoracic Surgeon, \\ Beijing Tuberculosis and Thoracic Tumor Research Institute, Beijing, P.R. China \\ ${ }^{2}$ Department of Clinical Immunology Laboratory, \\ Beijing Tuberculosis and Thoracic Tumor Research Institute, Beijing, P.R. China \\ Corresponding author: S.F. Xu \\ E-mail: xushaofa@263.net
}

Genet. Mol. Res. 9 (2): 765-771 (2010)

Received December 16, 2009

Accepted January 28, 2010

Published April 27, 2010

DOI 10.4238/vol9-2gmr740

\begin{abstract}
Monocyte chemoattractant protein 1 (MCP-1) is an important chemokine that has a dose-dependent anti-tumoral effect. Polymorphism in the MCP-1 distal regulatory region $(-2518 \mathrm{~A} / \mathrm{G})$ can affect the level of MCP-1 expression. We examined the polymorphisms of 112 unrelated patients with non-small-cell lung cancer (NSCLC) and 82 unrelated healthy controls of Han nationality in North China using PCRRFLP. We found that the distributions of AA, AG and GG genotypes of MCP-1-2518 were significantly different in NSCLC patients compared to controls $\left(\chi^{2}=10.106, \mathrm{P}=0.006\right)$. There was a significant increase in the frequency of the AA genotype (odds ratio $(\mathrm{OR})=3.138, \chi^{2}=8.905, \mathrm{P}$ $=0.003)$ and a significant decrease in the frequency of the GG genotype $\left(\mathrm{OR}=0.516, \chi^{2}=4.613, \mathrm{P}=0.032\right)$ in the NSCLC patients, compared to controls. The frequencies of AA, AG and GG genotypes did not differ in the NSCLC patients according to the number of pack-years smoked. Based on these results, we suggest that the MCP-1 $-2518 \mathrm{~A} / \mathrm{G}$ polymorphism is associated with genetic susceptibility to NSCLC.
\end{abstract}

Key words: Non-small-cell lung cancer; MCP-1; Gene frequency 


\section{INTRODUCTION}

Lung cancer is a common malignant tumor worldwide and now it has become the leading cause of cancer-related deaths (Jemal et al., 2008). In the past decade, the morbidity and mortality of lung cancer have markedly increased (Yang et al., 2004). There are two main types of lung cancer: small-cell lung cancer and non-small-cell lung cancer (NSCLC); NSCLC accounts for approximately $85 \%$ of all cases of lung cancer and its prognosis is poor (Visbal et al., 2004). Efforts at improving the poor prognosis of patients with NSCLC depend, in part, on a better understanding of the biology of lung cancer, including the effects of chemokines.

Monocyte chemoattractant protein 1 (MCP-1) is an important chemokine, and it is the third chemokine to be purified to homogeneity after platelet factor 4 and interleukin- 8 (Matsushima et al., 1989). MCP-1 has 76 amino acid residues, and its gene is located on 17q11.2-q12 (Rollins et al., 1991b). Being a chemokine, MCP-1 can be produced by many kinds of cells, including macrophages, lymphocytes, neutrophils, vascular endothelial cells, fibroblasts, keratinocytes, and several cancer cell lines (Mackay, 1997; Distler et al., 2001; Arndt et al., 2004; Lee et al., 2004; Mestdagt et al., 2006). Not only can it stimulate chemotaxis of peripheral blood monocytes and memory $\mathrm{T}$ cells, but it also induces calcium flux, respiratory burst activity and adhesion molecule and proinflammatory cytokine expression in monocytes (Rollins et al., 1991a; Jiang et al., 1992; Carr et al., 1994; Charo and Ransohoff, 2006). Thus, MCP-1 may play an important role in the biology of NSCLC. In fact, it has been demonstrated that MCP-1 is related to macrophage infiltration (Arenberg et al., 2000) and bone metastases (Cai et al., 2009) in NSCLC. However, to the best of our knowledge, studies on polymorphisms of MCP-1 -2518A/G in NSCLC are scarce.

In our study, we examined the polymorphisms of 112 unrelated patients with NSCLC and 82 unrelated healthy controls of Han nationality in North China using polymerase chain reaction-restriction fragment length polymorphism (PCR-RFLP). The aim of our study was to investigate the role of polymorphisms of MCP-1 $-2518 \mathrm{~A} / \mathrm{G}$ in genetic susceptibility to NSCLC.

\section{MATERIAL AND METHODS}

\section{Subjects}

The study enrolled 112 unrelated patients with NSCLC of Han nationality from North China. All patients were admitted to our hospital between October 2008 and February 2009, and the diagnosis of lung cancer was made histologically. The subjects ranged in age from 36 to 78 years; 67 of them were males and 45 were females. Forty-six patients were non-smokers and 66 patients were smokers; the mean pack-years of all smokers was $38.71(\mathrm{SD}=25.79)$. The 82 controls were unrelated healthy people of Han nationality from North China, 45 of them were males and 37 were females. All had undergone a chest X-ray check and did not show any anomaly. All subjects gave informed consent for this study.

\section{MCP-1 promoter genotyping}

Genomic DNA from patients and controls was extracted by standard techniques from peripheral blood leukocytes (Davis et al., 1980; Miller et al., 1988). The A to G polymorphism 
of MCP-1 at position -2518 was identified by PCR and RFLP. We used the EQ5.5-50 Easy$\mathrm{Do}^{\mathrm{TM}}$ PCR PreMix system (bought from SBS Genentech Co., Ltd., China), which contained $2 \mathrm{U}$ Taq DNA polymerase, $5 \mu \mathrm{L}$ 10X PCR buffer, $5 \mu \mathrm{L}$ loading dye and $5 \mu \mathrm{L}$ stabilizer. Added to the system were $2 \mu \mathrm{L}$ DNA, $2 \mu \mathrm{L}$ forward primer, $2 \mu \mathrm{L}$ reverse primer and $30 \mu \mathrm{L}$ pure water. The forward primer was 5'-TTCTCTTCTACGGGATCTGGG-3', and the reverse primer was 5'-GTCTCTCCTGGCTTAGTCAT-3'. PCR was performed under the following cycling condition: $95^{\circ} \mathrm{C}$ for $3 \mathrm{~min}$, followed by $94^{\circ} \mathrm{C}$ for $40 \mathrm{~s}, 59^{\circ} \mathrm{C}$ for $40 \mathrm{~s}$ and $74^{\circ} \mathrm{C}$ for $40 \mathrm{~s}$ for 35 cycles, with a final extension step at $72^{\circ} \mathrm{C}$ for $4 \mathrm{~min}$. Ten microliters PCR product was digested with $2 \mathrm{U} P v u \mathrm{II}$ in a final volume of $20 \mu \mathrm{L}$ that contained $2 \mu \mathrm{L} 10 \mathrm{X}$ enzyme buffer, for $16 \mathrm{~h}$. The resulting fragments were separated by electrophoresis on a $2 \%$ agarose gel and were visualized under UV light after staining with ethidium bromide.

\section{Statistical analysis}

Allele and genotype frequencies were calculated by direct counting. The Hardy-Weinberg equilibrium was determined by the Arlequin version 2.000 program. The frequency differences of alleles and genotypes between the different groups were estimated using the $\chi^{2}$ test with the SPSS version 13.0 program. The level of significance was set at $\mathrm{P}<0.05$.

\section{RESULTS}

\section{Mcp-1 genotyping}

The PCR products were 466-bp fragments. The fragments contained a unique $P v u \mathrm{II}$ restriction site, this restriction site is intact if $\mathrm{G}$ is at position -2518. Thus, the $P v u \mathrm{II}$ digestion DNA segment from G/G homozygous individuals would yield two fragments: 327 and $139 \mathrm{bp}$; DNA from G/A heterozygous individuals would yield three fragments: 466, 327 and $139 \mathrm{bp}$; DNA from A/A homozygous individuals would yield only one fragment: 466 bp (Figure 1).

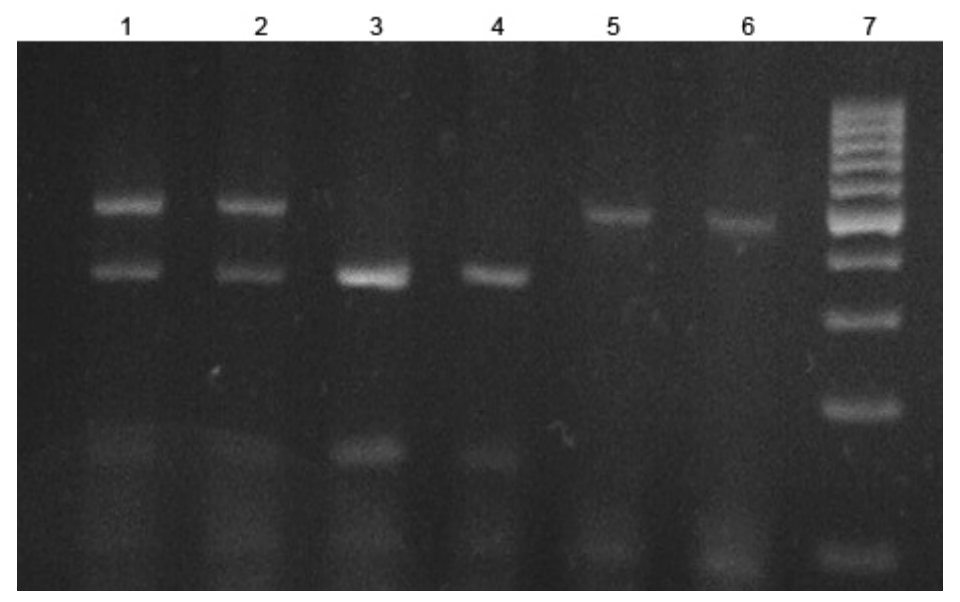

Figure 1. Three genotypes separated by electrophoresis. Lanes 1 and $2=$ AG genotype; lanes 3 and $4=\mathrm{GG}$ genotype; lanes 5 and $6=$ AA genotype; lane $7=100$-bp DNA marker. 


\section{Alleles and genotypes of MCP-1 in NSCLC patients and controls}

The distributions of AA, AG and GG genotypes of MCP-1-2518 did not deviate from the Hardy-Weinberg equilibrium $(\mathrm{P}>0.05)$ in both NSCLC patients and controls, and the distribution was significantly different in NSCLC patients compared to controls $\left(\chi^{2}=10.106\right.$, $\mathrm{P}=0.006$; Table 1). There was a significant increase in the frequency of the AA genotype (OR $\left.=3.138, \chi^{2}=8.905, \mathrm{P}=0.003\right)$ and a significant decrease in the frequency of the GG genotype $\left(\mathrm{OR}=0.516, \chi^{2}=4.613, \mathrm{P}=0.032\right)$ in NSCLC patients compared to controls. The frequencies of the $\mathrm{A} / \mathrm{G}$ alleles in the two groups were also different, the frequency of allele $\mathrm{A}$ was higher in lung cancer patients (Table 2).

Table 1. Hardy-Weinberg equilibrium and comparison of the distribution of the genotypes in non-small-cell lung
cancer (NSCLC) patients and controls.
\begin{tabular}{lcccccc}
\hline \\
\hline AA & GG & AG & $\chi^{2}$ & P & P of H-W equilibrium \\
\hline Normal & $0.122(10 / 82)$ & $0.415(34 / 82)$ & $0.463(38 / 82)$ & 10.106 & 0.006 & 1.000 \\
NSCLC & $0.303(34 / 112)$ & $0.268(30 / 112)$ & $0.429(48 / 112)$ & & & 0.137 \\
\hline
\end{tabular}

$\mathrm{H}-\mathrm{W}=$ Hardy-Weinberg

Table 2. Alleles and genotypes of MCP-1 in non-small-cell lung cancer (NSCLC) patients and controls.

\begin{tabular}{llllrr}
\hline & \multicolumn{1}{c}{ AA } & \multicolumn{1}{c}{ GG } & \multicolumn{1}{c}{ AG } & \multicolumn{1}{c}{ A } & G \\
\hline Normal & $0.122(10 / 82)$ & $0.415(34 / 82)$ & $0.463(38 / 82)$ & $0.354(58 / 164)$ & $0.646(106 / 164)$ \\
NSCLC & $0.303(34 / 112)$ & $0.268(30 / 112)$ & $0.429(48 / 112)$ & $0.518(116 / 224)$ & $0.482(108 / 224)$ \\
$\chi^{2}$ & 8.905 & 4.613 & 0.233 & 10.320 & 10.320 \\
P & 0.003 & 0.032 & 0.629 & 0.001 & 0.001 \\
OR (95\%CI) & $3.138(1.480-6.652)$ & $0.516(0.282-0.944)$ & & $1.963(1.301-2.962)$ & $0.509(0.337-0.768)$ \\
\hline
\end{tabular}

\section{Genotypes of MCP-1 in non-smokers and smokers with NSCLC}

Among the NSCLC patients, 46 were non-smokers and 66 were smokers. The frequencies of AA, AG and GG genotypes were 36.4, 27.3 and 36.4\% in non-smokers and 21.7, 26.1 and $52.2 \%$ in smokers, respectively. The difference was not statistically significant $\left(\chi^{2}=\right.$ $3.505, \mathrm{P}=0.173$; Table 3).

\begin{tabular}{|c|c|c|c|c|c|}
\hline & AA & GG & $\mathrm{AG}$ & $\chi^{2}$ & $P$ \\
\hline Non-smokers $(\mathrm{N}=46)$ & $0.217(10 / 46)$ & $0.261(12 / 46)$ & $0.522(24 / 46)$ & 3.505 & 0.173 \\
\hline Smokers $(\mathrm{N}=66)$ & $0.364(24 / 66)$ & $0.273(18 / 66)$ & $0.364(24 / 66)$ & & \\
\hline
\end{tabular}

\section{Genotypes of MCP-1 in NSCLC patients with different number of pack-years smoked}

According to the number of pack-years smoked, we divided the NSCLC patients into three groups: non-smokers and mild smokers ( 0 to $<16.1$ pack-years), moderate smokers (16.1 to $<30.3$ pack-years) and heavy smokers ( $\geq 30.3$ pack-years) (Gu et al., 2009). The frequencies of genotypes AA, AG and GG showed no difference in the three groups $\left(\chi^{2}=7.975, \mathrm{P}=\right.$ 0.092; Table 4). 


Table 4. Genotypes of MCP-1 in non-small-cell lung cancer patients with different pack-years smoked.
\begin{tabular}{lccccr}
\hline No. of pack-years & AA & GG & AG & $\chi^{2}$ & P \\
\hline 0 to $<16.1(\mathrm{~N}=54)$ & $0.185(10 / 54)$ & $0.296(16 / 54)$ & $0.519(28 / 54)$ & 7.975 & 0.092 \\
16.1 to $<30.3(\mathrm{~N}=30)$ & $0.400(12 / 30)$ & $0.200(6 / 30)$ & $0.400(12 / 30)$ & & \\
$\geq 30.3(\mathrm{~N}=28)$ & $0.429(12 / 28)$ & $0.286(8 / 28)$ & $0.286(8 / 28)$ & & \\
\hline
\end{tabular}

\section{DISCUSSION}

Being a potent chemokine, the influence of MCP-1 on monocytes and macrophages allows it to play an important role in inevitable tumor immunity. It has been demonstrated that MCP-1 can suppress tumor growth both in T lymphocyte-independent and lymphocytedependent manners, where the effect is notably dose-dependent (Rollins and Sunday, 1991; Walter et al., 1991; Manome et al., 1995). Rovin et al. (1999) found that the polymorphism in the MCP-1 distal regulatory region $(-2518 \mathrm{~A} / \mathrm{G})$ could affect the transcriptional activity and the level of MCP-1 expression. Under the same conditions, the MCP-1 production by monocytes from A/A homozygous individuals was the least, and from $\mathrm{G} / \mathrm{G}$ homozygous individuals was the most (Rovin et al., 1999). Thus, MCP-1 polymorphism may have some effect on tumor immunity and result in inconsistency of tumor susceptibility through the influence of MCP1 production. Vázquez-Lavista et al. (2009) studied the polymorphism of MCP-1-2518 and found that the distribution of AA, AG, and GG genotypes of MCP-1-2518 was significantly different in bladder cancer patients compared to controls $(\mathrm{P}=0.006)$. There was a significant decrease both in the frequency of $\mathrm{G}$ allele $(\mathrm{P}=0.021, \mathrm{OR}=1.752,95 \% \mathrm{CI}=1.088-2.828)$ and in the GG genotype $(\mathrm{P}=0.001, \mathrm{OR}=6.097,95 \% \mathrm{CI}=1.885-19.570)$ in transitional cell carcionoma patients, compared to controls (Vázquez-Lavista et al., 2009). It supported the supposition that MCP-1 polymorphism may partly affect tumor susceptibility.

Our results showed that the frequency of the AA genotype was higher in NSCLC patients than in controls $(\mathrm{P}=0.003, \mathrm{OR}=3.318,95 \% \mathrm{CI}=1.480-6.652)$, that the frequency of the GG genotype was lower in NSCLC patients than in controls $(\mathrm{P}=0.032, \mathrm{OR}=0.516,95 \% \mathrm{CI}$ $=0.282-0.944$ ), and that the frequency of the A allele was higher in NSCLC patients than in controls $(\mathrm{P}=0.001, \mathrm{OR}=1.963,95 \% \mathrm{CI}=1.301-2.962)$. These results are similar to those of Vázquez-Lavista et al. (2009). Therefore, we suggest that AA genotype individuals may have a higher susceptibility to NSCLC and that GG genotype individuals may have a lower susceptibility, mechanisms that may be related to the dose-dependent anti-tumor effect.

It is well known that there is a significant dose-response association between smoking and the risk of lung cancer (Jockel et al., 1998; Franco-Marina et al., 2006; Neuberger et al., 2006). Thus, we wanted to evaluate whether the smoking history can influence the association between genetic polymorphism of MCP-1 and NSCLC. First, we divided the NSCLC patients into non-smokers and smokers and found that the frequencies of AA, AG and GG genotypes showed no difference between the two groups. Second, we divided the NSCLC patients into three groups according to the number of pack-years smoked using the cut-off of a large sample-size study on smoking in Chinese people (Gu et al., 2009) and found that the frequencies of AA, AG and GG genotypes did not differ between the three groups.

In conclusion, our results suggest that the polymorphism in the MCP-1 distal regulatory region $(-2518 \mathrm{~A} / \mathrm{G})$ may be associated with susceptibility to NSCLC in the Han popula- 
tion of North China. As far as we know, this is the first study to show the association between MCP-1 polymorphism and NSCLC. In view of the small sample size and the limited ethnic variation among subjects (all subjects were of Han nationality from North China), additional large sample-size studies and studies in other populations are needed to confirm the association.

\section{ACKNOWLEDGMENTS}

We are grateful to patients and controls who took part in this investigation. Research supported by the Beijing Tuberculosis and Thoracic Tumor Research Institute.

\section{REFERENCES}

Arenberg DA, Keane MP, DiGiovine B, Kunkel SL, et al. (2000). Macrophage infiltration in human non-small-cell lung cancer: the role of CC chemokines. Cancer Immunol. Immunother. 49: 63-70.

Arndt PG, Suzuki N, Avdi NJ, Malcolm KC, et al. (2004). Lipopolysaccharide-induced c-Jun NH2-terminal kinase activation in human neutrophils: role of phosphatidylinositol 3-kinase and Syk-mediated pathways. J. Biol. Chem. 279: 10883-10891.

Cai Z, Chen Q, Chen J, Lu Y, et al. (2009). Monocyte chemotactic protein 1 promotes lung cancer-induced bone resorptive lesions in vivo. Neoplasia 11: 228-236.

Carr MW, Roth SJ, Luther E, Rose SS, et al. (1994). Monocyte chemoattractant protein 1 acts as a T-lymphocyte chemoattractant. Proc. Natl. Acad. Sci. U. S. A. 91: 3652-3656.

Charo IF and Ransohoff RM (2006). The many roles of chemokines and chemokine receptors in inflammation. N. Engl. J. Med. 354: 610-621.

Davis RW, Thomas M, Cameron J, St John TP, et al. (1980). Rapid DNA isolations for enzymatic and hybridization analysis. Methods Enzymol. 65: 404-411.

Distler O, Pap T, Kowal-Bielecka O, Meyringer R, et al. (2001). Overexpression of monocyte chemoattractant protein 1 in systemic sclerosis: role of platelet-derived growth factor and effects on monocyte chemotaxis and collagen synthesis. Arthritis Rheum. 44: 2665-2678.

Franco-Marina F, Villalba CJ and Corcho-Berdugo A (2006). Role of active and passive smoking on lung cancer etiology in Mexico City. Salud Publica Mex. 48 (Suppl 1): S75-S82.

Gu D, Kelly TN, Wu X, Chen J, et al. (2009). Mortality attributable to smoking in China. N. Engl. J. Med. 360: 150-159.

Jemal A, Siegel R, Ward E, Hao Y, et al. (2008). Cancer statistics, 2008. CA Cancer J. Clin. 58: 71-96.

Jiang Y, Beller DI, Frendl G and Graves DT (1992). Monocyte chemoattractant protein-1 regulates adhesion molecule expression and cytokine production in human monocytes. J. Immunol. 148: 2423-2428.

Jockel KH, Ahrens W, Jahn I, Pohlabeln H, et al. (1998). Occupational risk factors for lung cancer: a case-control study in West Germany. Int. J. Epidemiol. 27: 549-560.

Lee YW, Eum SY, Chen KC, Hennig B, et al. (2004). Gene expression profile in interleukin-4-stimulated human vascular endothelial cells. Mol. Med. 10: 19-27.

Mackay CR (1997). Chemokines: what chemokine is that? Curr. Biol. 7: R384-R386.

Manome Y, Wen PY, Hershowitz A, Tanaka T, et al. (1995). Monocyte chemoattractant protein-1 (MCP-1) gene transduction: an effective tumor vaccine strategy for non-intracranial tumors. Cancer Immunol. Immunother. 41: 227-235.

Matsushima K, Larsen CG, DuBois GC and Oppenheim JJ (1989). Purification and characterization of a novel monocyte chemotactic and activating factor produced by a human myelomonocytic cell line. J. Exp. Med. 169: 1485-1490.

Mestdagt M, Polette M, Buttice G, Noel A, et al. (2006). Transactivation of MCP-1/CCL2 by beta-catenin/TCF-4 in human breast cancer cells. Int. J. Cancer 118: 35-42.

Miller SA, Dykes DD and Polesky HF (1988). A simple salting out procedure for extracting DNA from human nucleated cells. Nucleic Acids Res. 16: 1215.

Neuberger JS, Mahnken JD, Mayo MS and Field RW (2006). Risk factors for lung cancer in Iowa women: implications for prevention. Cancer Detect. Prev. 30: 158-167.

Rollins BJ and Sunday ME (1991). Suppression of tumor formation in vivo by expression of the JE gene in malignant cells. Mol. Cell Biol. 11: 3125-3131.

Rollins BJ, Walz A and Baggiolini M (1991a). Recombinant human MCP-1/JE induces chemotaxis, calcium flux, and the respiratory burst in human monocytes. Blood 78: 1112-1116. 
Rollins BJ, Morton CC, Ledbetter DH, Eddy RL Jr, et al. (1991b). Assignment of the human small inducible cytokine A2 gene, SCYA2 (encoding JE or MCP-1), to 17q11.2-12: evolutionary relatedness of cytokines clustered at the same locus. Genomics 10: 489-492.

Rovin BH, Lu L and Saxena R (1999). A novel polymorphism in the MCP-1 gene regulatory region that influences MCP-1 expression. Biochem. Biophys. Res. Commun. 259: 344-348.

Vázquez-Lavista LG, Lima G, Gabilondo F and Llorente L (2009). Genetic association of monocyte chemoattractant protein 1 (MCP-1)-2518 polymorphism in Mexican patients with transitional cell carcinoma of the bladder. Urology 74: 414-418.

Visbal AL, Williams BA, Nichols FC III, Marks RS, et al. (2004). Gender differences in non-small-cell lung cancer survival: an analysis of 4,618 patients diagnosed between 1997 and 2002. Ann. Thorac. Surg. 78: 209-215.

Walter S, Bottazzi B, Govoni D, Colotta F, et al. (1991). Macrophage infiltration and growth of sarcoma clones expressing different amounts of monocyte chemotactic protein/JE. Int. J. Cancer 49: 431-435.

Yang L, Parkin DM, Li LD, Chen YD, et al. (2004). Estimation and projection of the national profile of cancer mortality in China: 1991-2005. Br. J. Cancer 90: 2157-2166. 